\title{
N-Methyl-D-aspartate and $\alpha$-amino-3-hydroxy-5-methyl-4- isoxazolepropionate receptors involved in the induction of sedative effects under an acute stress in neonatal chicks
}

\author{
H. Yamane $\cdot$ Y. Tsuneyoshi $\cdot$ D. M. Denbow $\cdot$ \\ M. Furuse
}

Published online: 31 March 2009

(c) Springer-Verlag 2009

Erratum to: Amino Acids (2009)

DOI 10.1007/s00726-008-0203-x

In the published original version of this article, first page, Abstract, 15th line, the information regarding the potency of NMDA ("less") is not given correct.

The correct sentence should read:

Although NMDA also induced a sedative effect, the potency of NMDA for sleep-like behavior was less than that of glutamate.

The online version of the original article can be found under doi: 10.1007/s00726-008-0203-x.

H. Yamane · Y. Tsuneyoshi · M. Furuse ( $\square)$

Laboratory of Advanced Animal and Marine Bioresources,

Graduate School of Bioresources and Bioenvironmental

Sciences, Kyushu University, Fukuoka 812-8581, Japan

e-mail: furuse@brs.kyushu-u.ac.jp

D. M. Denbow

Department of Animal and Poultry Sciences,

Virginia Polytechnic Institute and State University,

Blacksburg, VA 24061-0306, USA 